\title{
ERJ
}

Engineering Research Journal

Faculty of Engineering

Menoufia University

\section{Applying ePaedagogy and Blended Learning Resources in Electrical and Computer Engineering Programs Leading to International Accreditation}

\author{
Ashraf ZEIN EI Din \\ Faculty of Engineering \\ Menoufia University \\ Shebin ElKoum - Menofia, Egypt \\ ashrafzeineldin@sh-eng.menofia.edu.eg
}

\author{
Adrian Adăscăliței \\ Faculty of Electrical Engineering \\ Technical University "Gh. Asachi” \\ Iași, România \\ adrian.adascalitei@gmail.com
}

\begin{abstract}
:
The paper is about how to Using Blended Learning Resources in Electrical and Computer Engineering Programs Leading to International Accreditation.

OER (Open Educational Resources) and MOOC (Masive Open Online Courses), Virtual Learning Environments (for example moodle) are discussed.
\end{abstract}

Index Terms - Blended learning model for engineering, Electrical and Computer Engineering Program, ePedagogy, Virtual Learning Environment, International Acreditation, Open Educational Resources.

\section{INTRODUCTION}

The article presents the concept of using current pedagogical methods to meet the requirements for the Accreditation of Engineering Education Programs. Based on the analysis of the advantages of teaching model in the network environment, three teaching models based on multimedia and network environment, i.e. the teaching model of giving priority of lecturing, the teaching model of giving priority of independent learning and the teaching model of group learning, are discussed in the article. Processes of: design, development and implementation of interactive educational modules are presented, for the topic of electrical engineering and technology.

\section{ACCREDitation OF ENGINEERING EDUCATION (EE) IN EUROPE}

EUR-ACE (EURopean ACcredited Engineer) is a system for accreditation of EE programmes, first defined in 2006, that follows the main recommendations of the 2001 SEFI's position paper. In particular EUR-ACE respects the rich cultural diversity in $\mathrm{EE}$ among European $\mathrm{HE}$ Institutions. EUR-ACE has been developed with the support of a sequence of EC-DG EAC projects from 2004 to 2010. SEFI strongly supports the further development of the EUR-ACE System, as it constitutes the first and a successful example of panEuropean accreditation system in EE. It must be remembered that the learning objectives of EUR-ACE, defined in the EURACE Framework Standards, are fully compatible with the European Qualification Frameworks, apply to first and second level degrees, as well as "integrated (long) degree" programmes, and can be used also by institutions in countries that have not yet established a National engineering accreditation agency.
A. European Society for Engineering Education (SEFI). SEFI's position on Accreditation in EE:

One of the main goals of the accreditation of EE programmes is to ensure transparency and hence build TRUST, favouring mobility of students and engineers;

A European accreditation system for EE should respect the rich cultural diversity of European HE Institutions;

SEFI fully supports the development of the EUR-ACE System, since it is fully compatible with the requirement mentioned in the previous point, being based on cooperation and mutual recognition between existing National accreditation bodies, and being based on LO for its implementation;

SEFI also appreciates the fact that the EUR-ACE System has acquired global visibility through contacts with the Washington Accord, the Sydney Accord, and the whole International Engineering Alliance (IEA);

SEFI encourages all its HE institutional members to apply for EUR-ACE labels for their programmes;

SEFI encourages HE institutional members in countries that have not yet an established $\mathrm{EE}$ accreditation procedure to solicit the relevant authorities in this direction, and in the meantime to take advantage of the possibility to let one of the EUR-ACE-authorized agencies accredit (some of) their EE programmes;

SEFI wishes to ensure its strong support and involvement regarding ENAEE activities, and in particular supports the idea of submitting to the EC a new application to further advance the European system for accreditation of $\mathrm{EE}$, in which SEFI intends to play an active role. 


\section{USING THE WEB TO TEACH AND LEARN}

Traditional models of teaching (one-to-many communication supported with one-to-few encounters) does not sustain the quality of learning and teaching. e-Learning used creatively and effectively can offer support, maintain and enhance student learning.

A. The teacher's role in a networked learning environment changes:

-From lecturer to consultant, guide, and resource provider

-Teachers become expert questioners, rather than providers of answers

-Teachers become designers of student learning experiences rather than just providers of content $\bullet$ Teachers provide only the initial structure to student work, encouraging increasing self-direction

-Teachers present multiple perspectives on topics, emphasizing the salient points

-From a solitary teacher to a member of a learning team(reduces isolation sometimes experienced by teachers)

-From teachers having total autonomy to activities that can be broadly assessed

-From total control of the teaching environment to sharing with the student as fellow learner

-More emphasis on sensitivity to student learning styles

B. The student's role in a networked learning environment changes:

-From passive receptacles for hand-me-down knowledge to constructors of their own knowledge

-Students become complex problem-solvers rather than just memorizing of facts

-Students see topics from multiple perspectives

-Students refine their own questions and search for their own answers

-Students work as group members on more collaborative/cooperative assignments;

-group interaction significantly increased

-Increased multi-cultural awareness

-Students work toward fluency with the same tools as professionals in their field

-More emphasis on students as autonomous, independent, selfmotivated managers of their own time and learning process

-Discussion of students' own work in the classroom

-Emphasis on knowledge use rather than only observation of the teacher's expert performance or just learning to "pass the test"

-Emphasis on acquiring learning strategies (both individually and collaboratively)

-Access to resources is significantly expanded

C. The following definitions may help clarify the use of the Web for teaching.

Web-supported course- Any face-to-face course that uses a course website, including:

Web-enhanced course- A face-to-face course that includes a course website as a supplemental resource but does not require students to access materials or participate in activities via the course website;
Web-required course- A face-to-face course that requires students to access materials and/or participate in activities via the course website;

Web-exchange course- A face-to-face course that requires students to satisfy a specified number of contact hours via the course website

\section{Planning the COMPONENTS OF A WeB-SuPPORTED COURSE Website}

In order to enhance your face-to-face course by using the Web, there are two major uses: to make course content available to students and for online activities.

As in all courses, the quality of the instructional planning maximizes the learning for all students. In the Web environment, the components of a course website, which enhance teaching and learning and save time by being posted for students to access online, are especially valuable.

At the most basic level, instructors can post content and announcements at a course website. However, course planning usually begins with a course map - an outline of topics, weeks, objectives, activities, assignments, and assessments to show alignment of course components with each other in a weekly calendar format. Planning also includes the purposeful design of activities to create a student learning community supportive student groups in a course that develop with the students' active access, pursuit, generation, and evaluation of information and learning in their discussion, chats, and e-mail communications.

A. Course Website Components

Course content is aligned with curriculum standards, objectives, assignments, assessments.

\section{Website Organization}

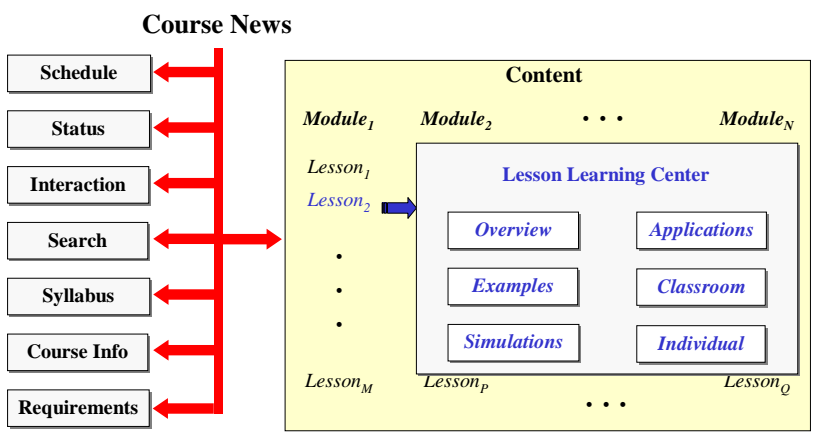

Figure 1 Website Organization

- Course Syllabus. The course contains a syllabus and supporting documents. The course includes items such as: course title; correct course semester; course description; course contact and credit hours; course prerequisites; course objectives; course assignment; course test schedule; required course materials; grading criteria; testing information; library resources; any on-campus requirements; work ethics information. 
- Staff Information. The course contains staff information: instructor name; appropriate picture (optional); e-mail address; telephone and fax numbers; office hours

- Student Information. The course contains a student orientation and explains: how to get started; technical equipment requirements; technology competency requirements; browser recommendations; drop deadlines; format for assignments; requirements for chat room and/or email; instructor response time; troubleshooting advice.

- Course Calendar - Due dates for readings, activities, assignments, quizzes, and exams

- Assignments and Activities, including directions and due dates. Course assignments

are designed: to be interactive and requires students to interact with: each other and their instructor via e-mail, chat room, and/or discussion board; and to address a variety of learning styles through: written assignments; reading activities; discussions; simulations; case studies; and give students the opportunity to engage in critical and abstract thinking. Students are challenged to complete one or more of the following: solve problems; apply concepts in context; complete practical applications.

- Course Documents - Additional documents for reference or study or answers to frequently asked questions. Course document section includes a variety of learning media. Includes course content delivered through media such as: PowerPoint presentations; Short lectures in audio or video format; links to resources on websites; CD-ROM materials.

- Lectures - Notes and audio to highlight key concepts of course content Caution: For face-to-face classes with webenhancement, faculty may wish to include required assignments, even if minor, for extra points to be turned in at the scheduled class times or other incentives to maintain class attendance.

- Communication Tools - Areas for sending and receiving email, participating in group or class discussions about particular issues, keeping electronic journals, completing "dry or simulated lab" exercises to prepare for "wet or real lab" experiences, or engaging in chat sessions. Many students are able and willing to participate more fully online than in faceto-face classes, especially when discussion assignments require each student to post a comment or the results of a brief assignment and to reply to a comment or question from other students.

- Student Tools - Areas for using a digital drop box to send and receive completed papers, homepages, or personal profiles of students, and access to grades.

- Assessment Tools- Areas for quizzes, exams, and surveys; online grade books; and assessment statistics. Course assignments are designed to be interactive and requires students to interact with: each other and their instructor via email, chat room, and/or discussion board. The course structure includes adequate and appropriate methods and procedures to measure student mastery of course competencies. Assessments include a variety of the following: online or proctored testing; standardized tests; projects; demonstrations; presentations; case studies.

\section{DEVELOPING MULTiMEDiA COURSE IN ELECTRICAL ENGINEERING.}

A. Example: EMC (Electromagnetic Compatibility) course Computer-Aided Learning is both a scientific and an engineering discipline containing five main components: 1) methodology: 2) theory of human computer interaction; 3) simulation and modeling methods; 4) development of dedicated hardware; 5) application of data-bases and knowledge-bases.

The management activities to develop a multi-media course in EMC must be considered: learning styles, learning environments, and instructional activities.

There are four management arrays through five project phases (analysis, design, production, implementation, evaluation): 1) planning (arranges conditions and prepares plans for project activities); 2) controlling (deliver communications among team members and outside people); 3) communicating (stimulate, monitor, criticize, and modify project activities): 4) documenting (document materials and products).

Course Objectives: The entry into force of the EEC Directive $336 / 89$ on the electro-magnetic compatibility gave a big boost to regulatory activity within the context of national and European markets.

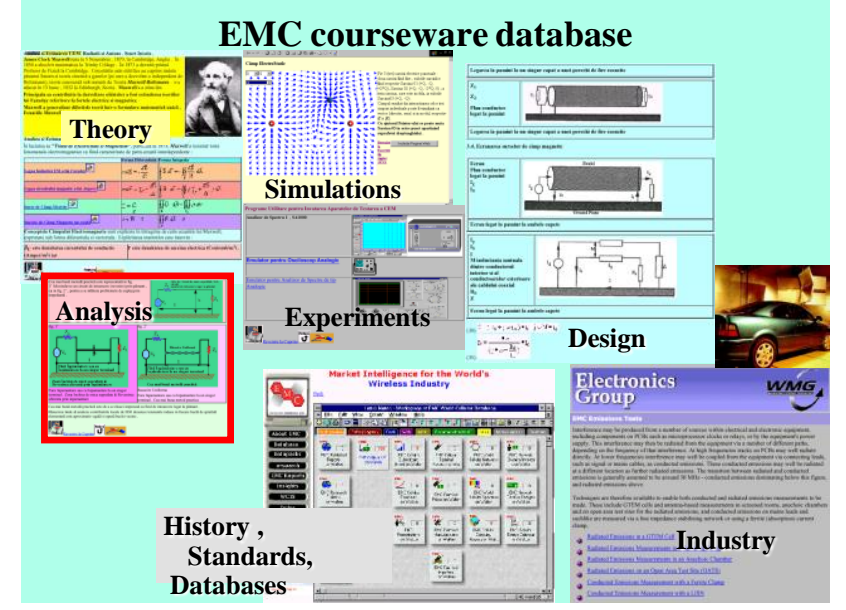

Fig. 2. EMC courseware database

Many manufacturers and users of electrical and electronic equipment are now faced with legal obligations in a field where their previous interest may have been only peripheral. To place their products on the market or to take equipment into service, certain actions must be taken in respect of design, construction, manufacture, certification and installation in order to satisfy the minimum market entry requirements. In the process of transition towards a market economy, Romania must reconsider the engineering education process in order to produce a new type of engineer with new skills and attitudes. They should understand the inter-relationship between various engineering fields; principles of scientific investigation and methodology of engineering design should be well mastered. So, the use of computer in engineering education is a must.

The objectives of this course are: 1 . To gain an understanding of EMC principles and their application to data acquisition and 
analysis; 2. To properly implement, through laboratory experimentation, various sensors and transducers in order to understand the application of each; 3. To design instrumentation systems; including both hardware and signal processing considerations.

Course Outline: Electromagnetic interference (EMI) is defined to exist when undesirable voltages or currents are present to influence adversely the performance of an electric/electronic circuit or system. Electromagnetic compatibility (EMC) is the capability of the equipments or systems to be operated in their intended operational environment at designed levels of efficiency without causing or receiving degradation owing to unintentional EMI.

EMC is the result of an engineering planning process applied during the life cycle of the equipment. Tire process applied during the life cycle of the equipment. The process involves careful considerations of frequency allocation, design, procurement, production, site selection, installation, operation, and maintenance.

Homework will be assigned on a weekly basis. It is to be completed individually, though interaction with ones fellow students is encouraged.

Laboratory Work: A laboratory experiment will be assigned each week. A well documented lab book must be kept to record all pertinent data, and in which to draw results and report on the findings of the lab work.

Final Project: A final, comprehensive design project will be completed in the last four weeks of the course. Everybody will submit an initial feasibility study for the final project and an individual final project report. Cross-major teams are strongly encouraged.

Exams: There will be a midterm exam. A final comprehensive exam will also be given.

Quizzes will be used as a means of providing quick feedback. All the quizzes together will count $5 \%$ or less (probably much less) of the final grade and will be considered as part of the homework grade.

\section{General PRESENTATION FF OPEN EdUCATIONAL RESOURCES AND MOOCS}

Open Educational Resources (OER) have the potential to broaden access to education and to improve the quality and cost-effectiveness of teaching and learning in Europe. The best way to put OERs into practice is through Massive Open Online Courses (MOOCs). MOOCs are large-scale courses that represent one of the latest developments in open education, an initiative that is always trying to improve quality, access and equality in education and training.

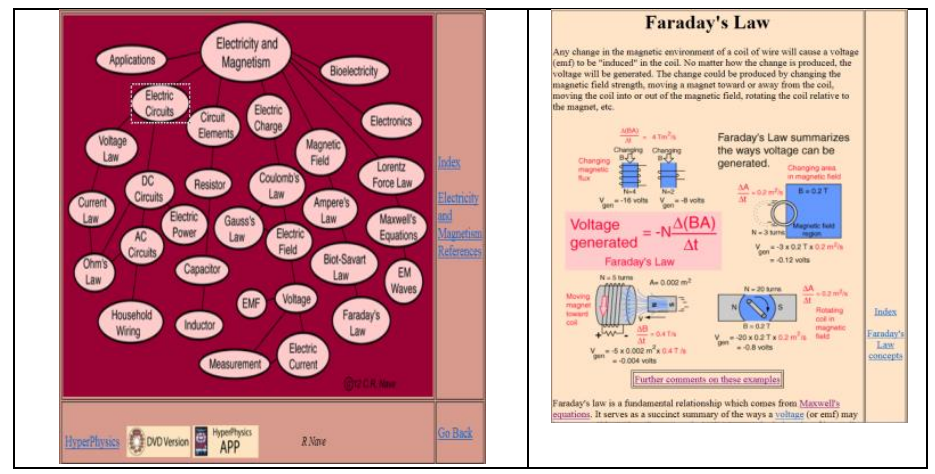

Fig. 3. Hyperphysics, Electricity and Magnetism, http://hyperphysics.phyastr.gsu.edu/hbase/emcon.html\#emcon

MOOCs can be implemented in formal, informal and nonformal learning, and make learning ubiquitous.

Project will use leading-edge technology to create a combined Moodle MOOC platform- based on individual platforms and resources provided by project partners - making it possible to combine and transfer pilot activities in all the hubs involved. Project will contribute to increasing awareness of the advantages of open education in Europe. The project will prove the potential of MOOCs (courses and communities) for breaking down technological barriers in learning across people with special needs or at risk of exclusion.

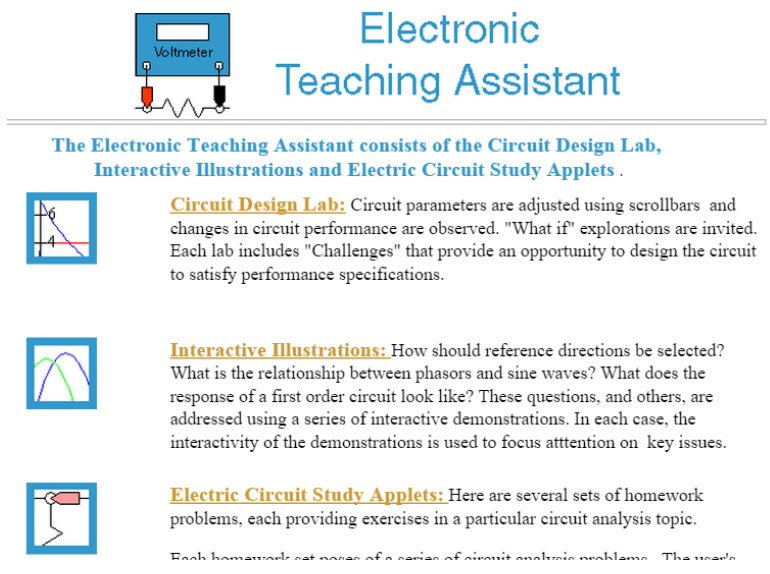

Fig. 4. The Electronic Teaching Assistant: the Circuit Design Lab, Interactive Illustrations and Electric Circuit Study Applets

MOOCs adopted definition: MOOC is an online course designed for large number of participants that can be accessed by almost anyone anywhere as long as they have an internet connection, is open to everyone without entry qualifications and offers a full/complete course experience online for free.

A MOOC includes educational content, facilitation interaction among peers (including some but limited interaction with academic staff), activities/tests, including feedback, some kind of (nonformal) recognition options and a study guide / syllabus. 
Utilising the Virtual Lessons and Laboratory Resources for Electrical Engineering

Teaching electrical engineering laboratory procedures by means of a virtual laboratory on a personal computer will be much welcome by educational institutions for whom maintaining a hands-on electric engineering lab is not viable due to various reasons. Instructional laboratory simulations can be incorporated in the virtual laboratory resources where students are free to make the decisions they would confront in an actual laboratory setting.

Electrical Engineering and Technology eLearning Resources

Real-life situations and problems are faced by them, where they have to make/take decisions and face the consequences thereof.

\section{ONLINE EDUCATION BASED UPON STUDENT LEARNING STYLES}

Some strategies that have been taken to accommodate a variety of student learning styles in the Electric Engineering Course are outlined below as an example. Active Learners prefer trying things out and working with others. Practical sessions require students to perform laboratory experiments in small teams of 2-3 students. During these sessions, practical supervisors will ask students questions related to the experiment. Students will submit team reports on performed experiments and all students in a team are required to contribute to writing each report. Reflective Learners prefer to think things out and work alone. Study guide and the course web site contain all necessary information about the material to be covered in lectures and practical sessions.

Students are advised to prepare for all classes by reading from the textbook and other resources. This allows students to reflect on material being presented.

Sensing Learners like learning facts and using tried methods in practical settings. Practical sessions will be supported by detailed guidelines on how to perform experiments. Also practical supervisors will be available for help with the procedures. A number of typical problems will be solved during tutorial sessions and step by step procedure explained. Also practical sessions are good hands-on opportunity for relating theory and practice. Intuitive Learners are innovative and enjoy abstract concepts. Practical sessions will be accompanied with a number of questions to be answered by students in their reports.

\section{INSTRUCTIONAL PROCESS IN ACTIVE CLASSROOM}

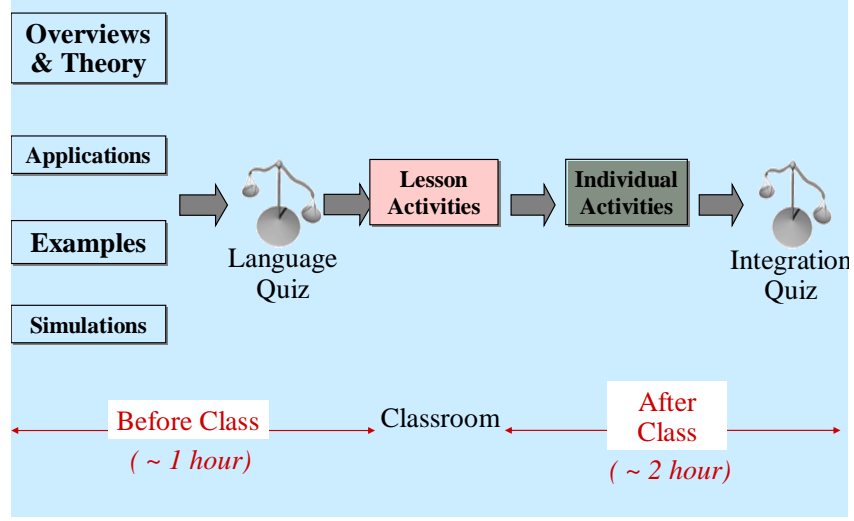

Fig. 5. Instructional process in active classroom

These questions are of various-graded level of difficulty and are aimed to enforce students' abilities to draw conclusions that link practical results with the theory. Visual Learners relate well to graphs, pictures, diagrams etc. All lectures will be presented in power point mode with lots of diagrams to allow students visualization of electrical circuits, which are by their nature invisible. Wherever possible, interactive and other multimedia material will be used to support visual learning style. Verbal Learners enjoy reading and lectures. Students will be required to write four reports based on experiments done in the laboratory. Report writing will support development of verbal learning style as well as development of technical writing skills that are important in engineering practice. Students will also be encouraged to discuss material using electrical engineering jargon. Use of the course textbook and the study guide is largely verbal.

Sequential Learners prefer taking logical steps toward an outcome. Material will be presented starting from fundamental concepts towards more advanced topics. Although some topics may seem not to be related they may be related in the similar concepts used to understand different systems like electrical vs. magnetic circuit.

Therefore it is important for students to attend regularly all classes and follow the sequence of the material presented. Global Learners grasp the big picture quickly and work out the steps later. This course is designed to give students a global overview of electrical circuit theory and various methods for analyzing electrical circuits. The course introduces students to global concepts and then case studies are analyzed to enforce students' understanding of application of learned principles in various specific cases. All students may be tested for their preferred learning styles and be given detailed information on how to interpret test results and how to use this information to make their learning more effective. The teaching arrangements in this course also aims to expand the students' learning styles, therefore it is important for students not only to practice their preferred leaning styles but to try to develop other learning styles using techniques more suitable for these styles. 


\section{InSTRUCTIONAL PROCESS}

The instructor interacts routinely with students. Initiates contact on the: first day of class; daily through drop-add period; at least three times per week thereafter. The instructor monitors student activity adequately: contacts students who are having difficulties; checks course statistics to note frequency of student login.

The instructor provides adequate student support, responds to student e-mails promptly, provides substantive and timely responses to assignments and tests. The instructor is accessible to students, maintains office hours at different times of the day to be accessible to working students, posts lack of availability when sick or travelling, informs students of weekend e-mail policy.

Learning Process:

Before Attending Class:

- Explore the Overviews \& Theory, Examples, Applications, and Simulations sections for the Lessons to be covered in the Classroom Activities. (See Schedule).

- Complete Language Quizzes for Lessons to be discussed in class.

Classroom Activities:

- Attend class!

- Be prepared to contribute!

- Active learning environment with team-based problems solving.

- Web ready solutions from each team are due by the end of the week (Friday at $5 \mathrm{pm}$.)

After Attending Class:

- Complete team-based analysis and design problems assigned in the classroom activities.

- Optional analysis and design problems are available on the website.

- Complete the Integration Quizzes for Lessons covered in class.

The student stays in contact with instructor, demonstrates class attendance by various means as directed by online instructor which may include e-mails, submitting work, chat rooms, and/or discussion boards.

The instructor incorporates work ethics into course instruction, advises students of the work ethics topic of the week and utilizes activities related to the topic. Instructor ensures student participation by requiring e-mail or other online method of confirmation such as discussion board.

The instructor ensures that the course is qualitatively consistent with same traditional course, strives toward consistency between traditional and online courses.

\section{CONCLUSIONS}

We developed a framework to teach systematic problemsolving skills and allow students to complete interactive exercises at their own pace. Conventional web-based exercises tend to take two major forms: multiple-choice questions and short problems asking students to fill in numerical answers. The multiple-choice question format, even in a regular classroom, tends to encourage guessing or elimination to arrive at the correct answer.

While the ability to guess or to eliminate incorrect answers is desirable, the lower-level courses need to teach students how to use basic theory to arrive at the correct answer. The implementation of this format on the web leads to another undesirable learning characteristic: students can get to the correct answer after several wrong clicks without even guessing. There is essentially no learning involved in this fastclick exercise. The short-problem format, with filled-in boxes, avoids these drawbacks but fails to teach students how to proceed step-by-step from the problem statement to the correct solution. The systematic problem-solving skill is the major learning outcome of low-level engineering courses, and webbased instruction needs to provide methods to teach this skill. Our web-based instructional methodology focuses on teaching this systematic problem-solving skill.

The development of courseware materials for Student Engineers in Romania will have an increasing impact on the national scene of Engineering Education.

The research and development of online materials devoted to the development of human resources and human potential will accelerate the process of transfer of up-to-date technology. if new information and communication technologies are introduced in order to enhance Independent / Autonomous Learning in the context of Information Society to be introduced in Electrical and Computer Engineering Education. Improving the quality of education through the diversification of contents and methods and promoting experimentation, innovation, and best practices are Technical universities' strategic objectives in education. With the emerging new information and communication technology, the teaching profession is evolving from an emphasis on teacher-centred, lecture-based instruction, to student-centred, interactive learning environments. Designing and implementing successful ICT-enabled teacher education programmes is the key to fundamental, wide-ranging educational reform.

Mentoring (or coaching) is rapidly becoming recognised worldwide as a highly effective means of improving our knowledge and skills. Mentoring is used by large organisations to induct new personnel, provide support for their personal development, help with career progression, help with change programmes, to name a few, but it has now spread outside of the grasp of these organisations. Mentoring is now being used in schools, universities, for social programmes, support of businesses etc. Just scan the internet and you will come up with many more!

The article provides resources to help teacher educators, administrators and policymakers better apply ICTs to teacher education programmes. The resources were developed by Departments for Teachers Education with extensive experience in the integration of ICTs into teacher preparation programmes. 


\section{ACKNOWLEDGMENT}

We wish to address our thanks to all authors and institutions for the value of their ideas, concepts and information that we used in our project design. All sources are cited in the bibliography.

\section{REFERENCES}

[1] European Network for Accreditation of Engineering Education (ENAEE), http://www.enaee.eu/

[2] SEFI Position Paper on Accreditation of Engineering Education, http://sefibenvwh.cluster023.hosting.ovh.net/wp-

content/uploads/2017/08/SEFI-Position-Paper-on-Accreditation-20121.pdf

[3] Bloom, B. S., et al. Taxonomy of Educational Objectives, Handbook I: The Cognitive Domain. 1956. New York: David McKay Co Inc, 1964.

[4] J.A. Svoboda: The Electronic Teaching Assistant: the Circuit Design Lab, Interactive Illustrations and Electric Circuit Study Applets . http://people.clarkson.edu/ jsvoboda/eta/

[5] Špaldonová, Darina, and Milan Guzan. "Application of Excel in threephase circuit analysis."Acta Electrotechnica et Informatica No 6.1 (2006): 4. http://aei.tuke.sk/papers/2006/4/Guzan.pdf

[6] Enache, S., Campeanu, A., Enache, M. A., \& Ivanov, S. (2007). Elearning tools for education in asynchronous machines. WSEAS transactions on advances in engineering education, 4(11), 238-241.

[7] JAVA Applets for Electrodynamics, www.walter-fendt.de/ph14ro

[8] Learning objects that cover a broad-based electromechanical engineering program, http://electronics.wisc-online.com/; and https://www.wisconline.com/learn/technical/

[9] Engineering Open Educational Resources, http://guides.oer.hawaii.edu/engineeringOER

[10] Interactive simulations, http://phet.colorado.edu/en/simulations/translated/en

[11] Open Courseware Consortium, www.ocwconsortium.org/
[12] Online Repositories for Open Educational Resources, http://www.cincinnatistate.edu/online/faculty-resources/onlinerepositories-for-open-educational-resources

[13] MIT Open Courseware (OCW), Electrical Engineering and Computer Science, http://ocw.mit.edu/courses/electrical-engineering-andcomputer-science/

[14] Moodle elearning, Electrical Engineering Faculty, Technical University "Gh. Asachi”" Iași, România http://moodle.ee.tuiasi.ro/

[15]Lu, Jingyan, and Nancy Wai Ying Law. "Understanding collaborative learning behavior from Moodle log data." Interactive Learning Environments 20.5 (2012): 451-466.

[16] M. D. Filipovic, Understanding Electronics Components, http://www.mikroe.com/old/books/keu/00.htm

[17] College Open Textbooks, Engineering \& Electronics http://colle geopentextbooks.org/textbook-listings/textbooks-bysubject/engineeringandelectronics

[18] EECS Course WEB Sites, http://inst.eecs.berkeley.edu/classeseecs.html; http://media.pearsoncmg.com/ph/chet/chet_electronics_student_1/

[19] Pearson Electronics Student Supplement Site! http://media.pearsoncmg.com/ph/chet/chet_electronics_student_1/

[20] Electric Power Engineering Courses, http://elearning.utm.md/moodle/course/category.php?id=7

[21] Electric circuits Craiova University, http://em.ucv.ro/elee/EN/realisations/CircuitsElectriques/index.htm 